\title{
Levee breach-induced compound flood modeling in Qianbujing Creek, Shanghai during Typhoon "Fitow"
}

\author{
Yuhan Yang ${ }^{1}$, Jie Yin ${ }^{1}$, Weiguo Zhang ${ }^{1}$, Yan Zhang ${ }^{1}$, Yi Lu ${ }^{1}$, Aoyue Xiao ${ }^{1}$, Yunxiao \\ Wang $^{1}$, and Wenming Song ${ }^{1}$ \\ ${ }^{1}$ East China Normal University
}

April 27, 2021

\begin{abstract}
Levee breach-induced flooding occurs occasionally but always causes considerable losses. A serious flood event occurred due to the collapse of a 15-m-long levee section in Qianbujing Creek, Shanghai, China, during typhoon "Fitow" in Oct, 2013. Heavy rainfall associated with the typhoon intensified the flood extent. This study investigates the flood evolution to understand the dynamic nature of flooding and the compound effect using a well-established 2D hydro-inundation model (Floodmap) to reconstruct this typical event. Our simulation results provide a comprehensive view of the spatial patterns of the flood evolution. The worst-hit areas are predicted to be low-lying farmland. Temporal evaluations suggest that the most critical time for flooding prevention is in the early hours after dike failure. In low-elevation areas, temporary drainage measures and flood defenses are equally important. The validation of the model demonstrates the reliability of the approach.
\end{abstract}

\section{Hosted file}

Manuscript.pdf available at https://authorea.com/users/410245/articles/519707-levee-breachinduced-compound-flood-modeling-in-qianbujing-creek-shanghai-during-typhoon-fitow
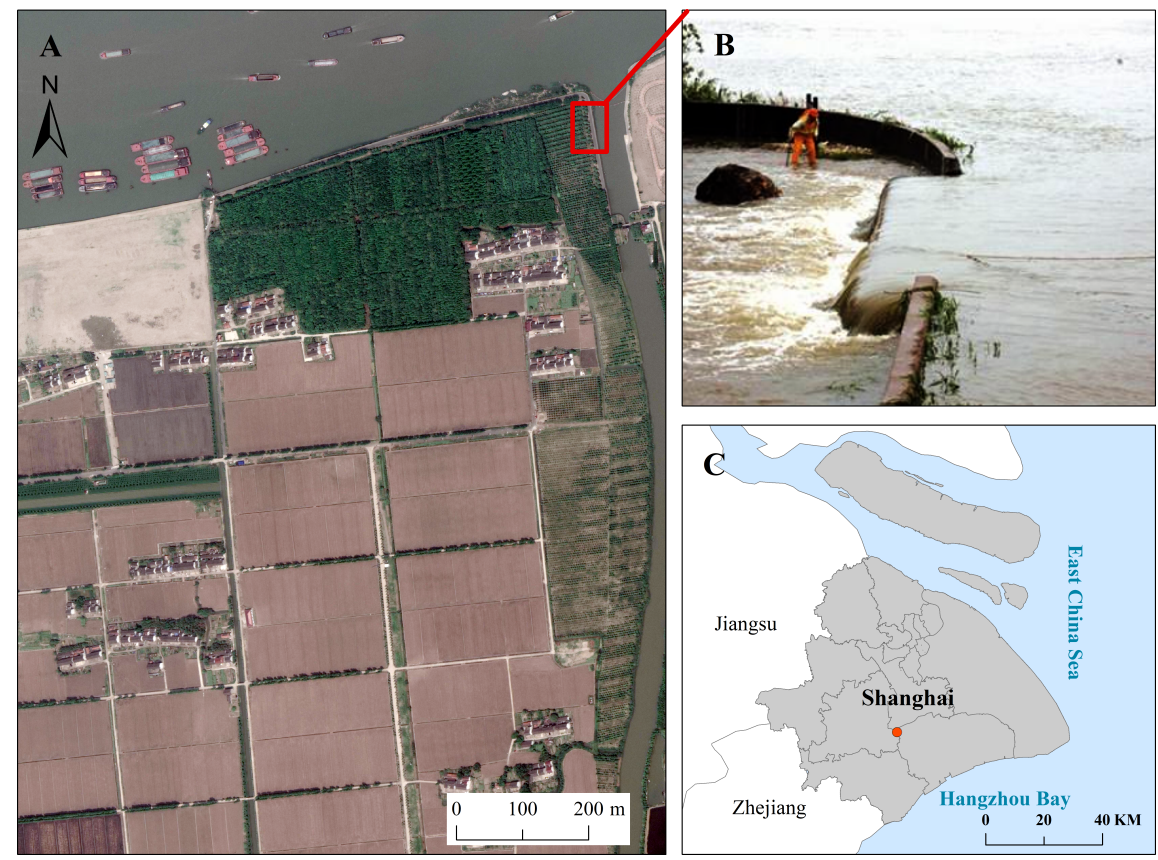

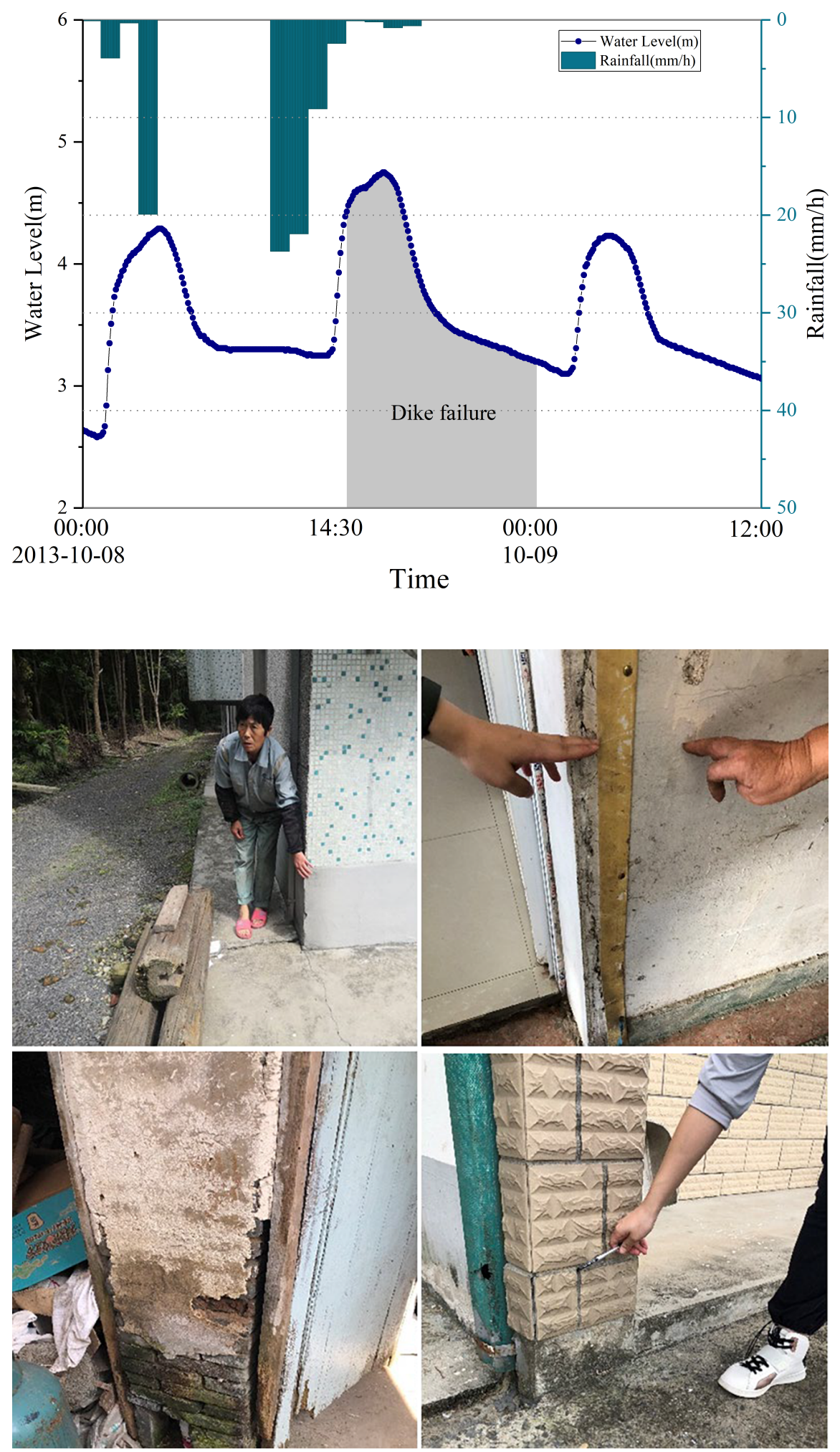

Hosted file 
Figure 4.eps available at https://authorea.com/users/410245/articles/519707-levee-breachinduced-compound-flood-modeling-in-qianbujing-creek-shanghai-during-typhoon-fitow

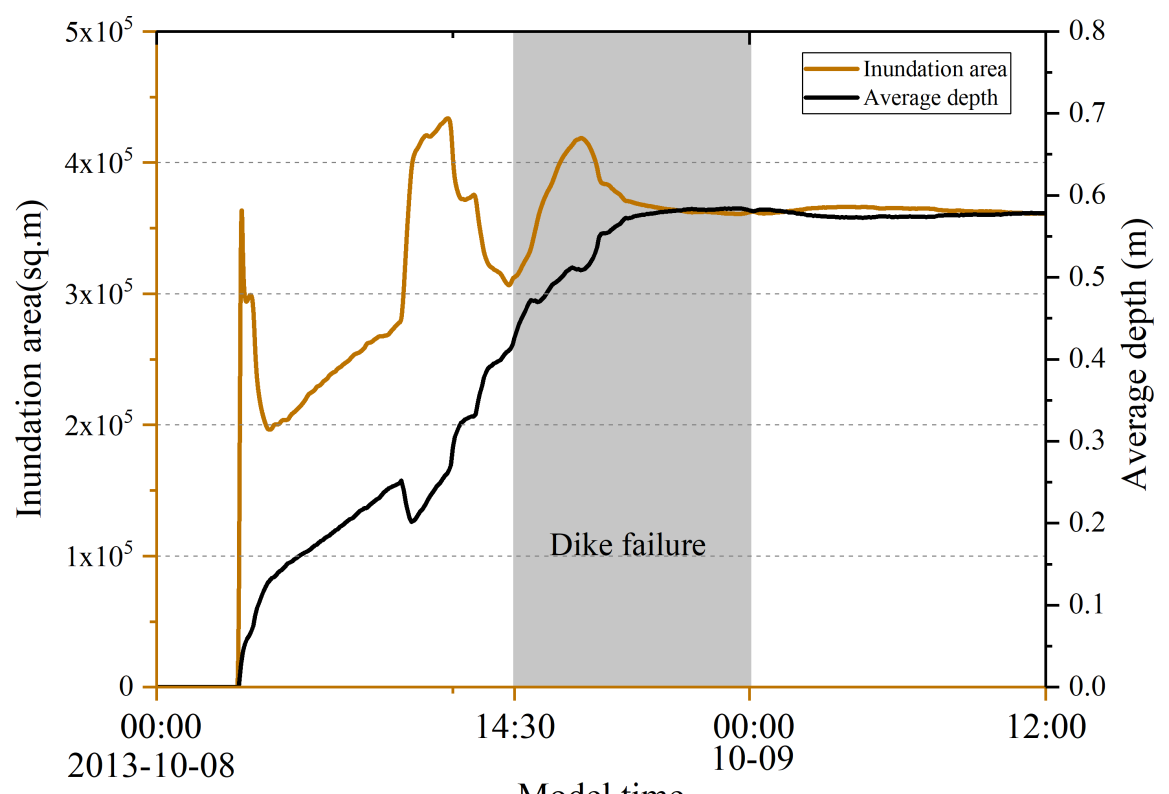

Model time 


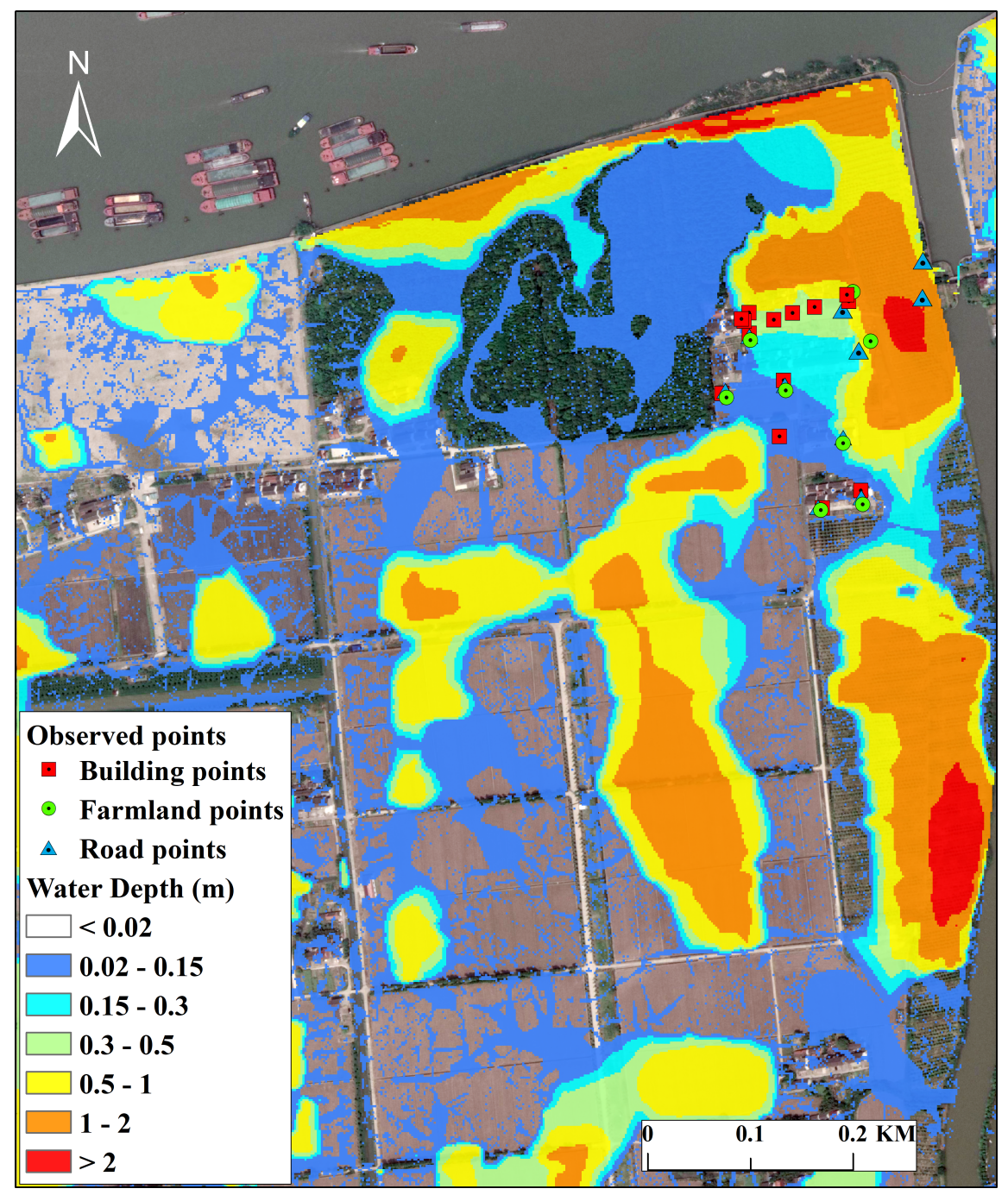



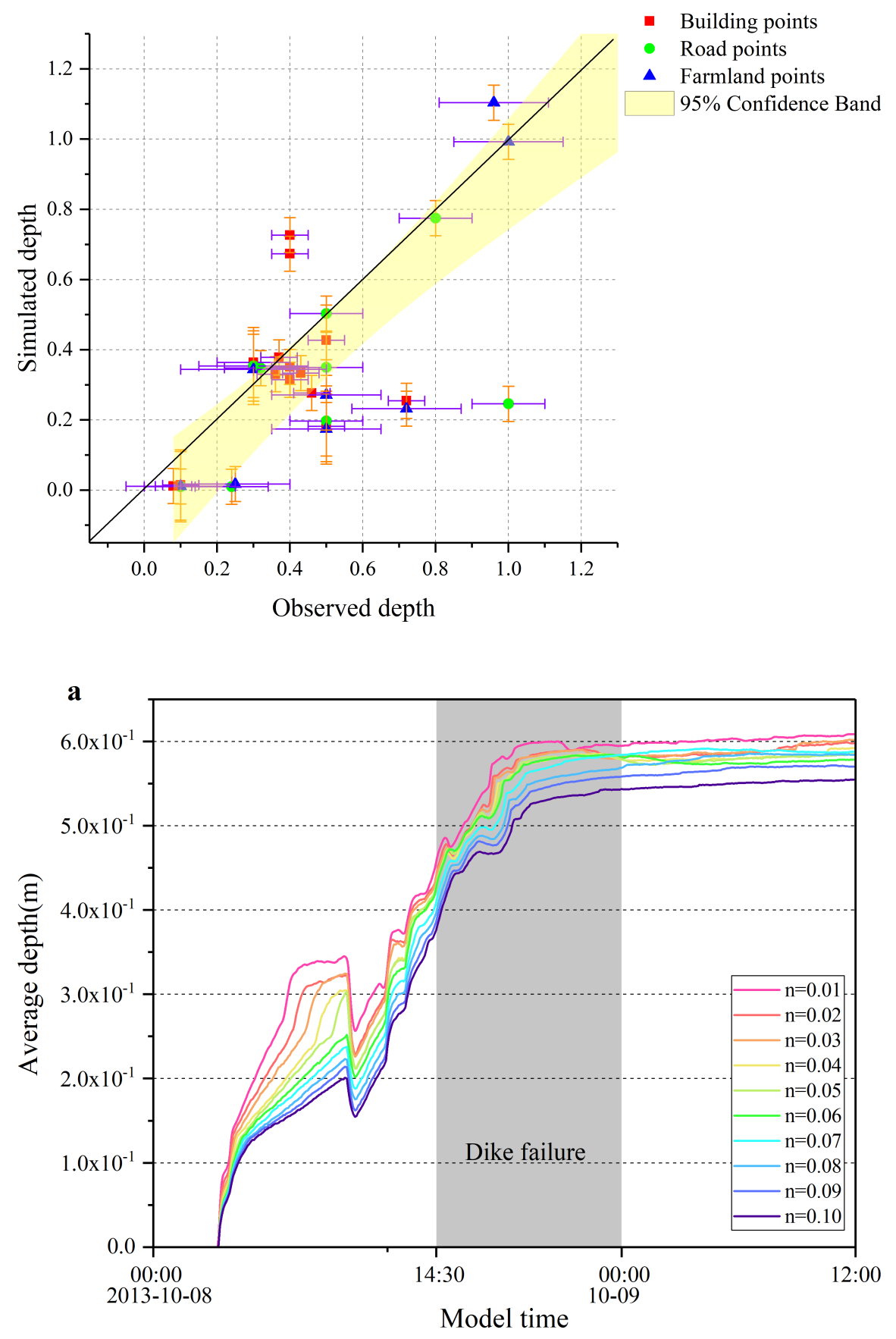


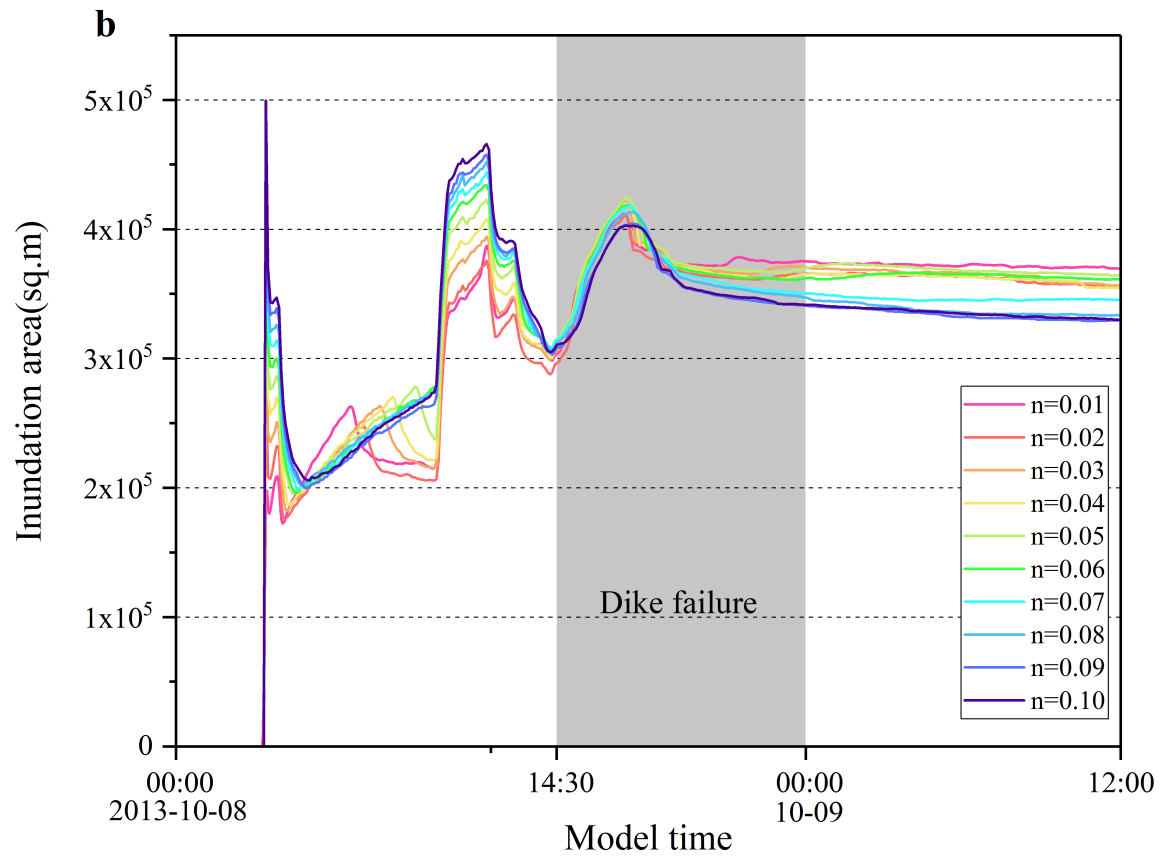

